\title{
Growth and Sex-Factors of Racial Character.
}

$A^{T}$ a meeting of the Royal Anthropological Institute held on February 28, Dr. W. H. R. Rivers, president, in the chair, Miss R. M. Fleming read a paper on "Growth and Sex-Factors in Racial Analysis." Her results were based on a large number of measurements made, for the most part, in Wales, the measurements in the case of the children having been repeated at regular intervals.

Miss Fleming said periodic re-measurement of children during growth shows that-

I. Boys and girls have different growth cycles as regards features used in racial analysis ;

2. Head breadth commonly increases more than head length., so the cephalic index usually rises during growth. Cephalic index of girls rises most quickly between the third and eighth years, while in boys it does so especially after the tenth year. Changes of one unit in one year were general, and larger changes frequent;

3. The frequent darkening of hair and eye seen in both sexes shows the same difference of period, and also confirms the results of Pryor's work on ossification of wrist bones ;

4. There are clear correlations between facts of physical growth and mental development, and these correlations should influence educational methods.

British women show more development of pigment, brachycephaly, and prognathism than do men. Sixty per cent. of any normal sample of men have cephalic index 75-79; nearly the same proportion of women have indexes $77-8 \mathrm{r}$. Men outnumber women under 75 and women enormously outnumber men over 84 . Men have the glabella stronger and women the occiput larger in most cases, but this does not account for the difference, which is one of growth.

Among the types noted are the following :

a. Dark-haired, dark-eyed women, head length I 8I-I93, head breadth I43-I54, cephalic index $77-8 \mathrm{I}$, calvarium rather low, prognathism slight or absent, forehead usually full, occipital prominence marked and low.

About 5o per cent, of the sample of women studied possessed most of these characters, and they were very marked among the Welsh people.
This group corresponds with Fleure's group of men of indexes 75-79, dark colouring, but the women show greater heterogeneity;

b. Dark-haired, dark-eyed women, head length I87-199, head breadth $137-148$, cephalic index 76 or less. Bony development more marked and head height greater than in " $a$,". forehead more often receding, prognathism often marked. A remote hill country pedigree is common for this type, and one often finds flattened nostrils, deepset eyes, hair low on the forehead. A few are darker in youth than later on. Intellectual distinction is frequent.

c. Light-haired, light-eyed women, head length I $80-192$, head breadth I45-I53, but measurements a little lower in general than in " $a$ " and " $b$." Prognathism absent or very slight, bizygomatic breadth small, face long, calvarium finely arched, forehead often retreats, bones strong, stature averages 3 inches more than in " $a$ " and " $b$." Type less frequent than " $a$ " and " $b$ " among purely Welsh peoples.

d. Fair longheads, very narrow, breadth about I32-I37, low foreheads, slight build, low vitality.

It is not suggested that this group has any historical or racial significance. The fair and dark broadheads have not yet been examined in sufficient numbers to warrant discussion, especially as the analysis of male broadheads has not yet proceeded very far.

A discussion followed the reading of the paper, in the course of which Prof. Parsons pointed out that Miss Fleming's work corroborated the results. which he himself had obtained both as regards the conclusion that the breadth of head of women was greater than that of men in the corresponding series, and that women were darker. Prof. Fleure said that Miss Fleming's work represented a real advance in the attempt to provide a sure foundation for physical anthropology, while it showed that the conclusions of Prof. Boas as to the change in head form of immigrants in the United States were unsound. Several speakers emphasised the importance of Miss Fleming's results for the educationist in connection with the classification and grading of children of both sexes.

\section{Mortality Tables.}

THE Privy Council Medical Research Council has published as the sixtieth of its Special Report Series a valuable memoir by Dr. Brownlee, the director of statistics of the council, on the use of death-rates as a measure of hygienic conditions (H.M. Stationery Office, I922, 80 pp., $3 s$. net). Some of the methods employed for that purpose are likened by Dr. Brownlee to those of the tailors of Laputa. He divides the subject into two parts: (I) deathrates in general and (2) mathematical treatment, and illustrates it by 30 tables and 16 diagrams. On special points he has had recourse to Sir Alfred Watson, whose great experience in the construction of mortality tables must have been valuable.

The crude death-rate on a large population requires adjustment and correction. When applied to sections of the population, as to those dwelling in certain districts or those engaged in specified occupations, the liability to error is greatly increased. The method by which these are corrected is called "standardising."

For the purpose of life-tables the death-rate is taken to signify the ratio of the number of deaths of persons above any defined age, to the number living above that age, in a stationary population. They show some disadvantage in using standardised deathrates. So far back as 1875 the late Dr. Wm. Farr was sensible of this difficulty, and devised a method for meeting it, which Dr. Brownlee considers to present great advantages. Prof. Karl Pearson held that causes of death might be specially grouped to correspond with periods of life. Dr. Brownlce gives a re-drawing of Prof. Pearson's diagram (Trans. Roy. Soc., I 894) representing the curves for infantile mortality and the mortality of childhood, youth, middle age, and old age respectively.

The tables of Dr. Farr, based on returns from I 86I to 1870 , provide information as to causes of death for selected districts according to sex and age. Later tables calculated by Mr. George King, the eminent actuary, show that the same conditions still hold. Dr. Brownlee supplies a table giving a summary of observations in various districts from I 838 to I9I2, and comparing the standardised death-rates with the life-table rates for each observation. Though a life-table death-rate is the criterion of ultimate

$$
\text { N่D. } 2734 \text {, VOL. IO9] }
$$

